\title{
PROFIL PSIKOGRAFIS \& PENGGUNAAN MEDIA PADA KELOMPOK MILENIAL PENGUNJUNG KEBUN BINATANG SURABAYA
}

\author{
A.A.I Prihandari Satvikadewi', Herlina Kusumaningrum², \\ 1, 2)Program Studi Ilmu Komunikasi, FISIP, Universitas 17 Agustus 1945 (UNTAG) \\ Surabaya, \\ Email : vika@untag-sby.ac.id
}

\begin{abstract}
Surabaya Zoo as a recreational facility that is officially managed by the Surabaya City Government and has the status of a Regional Company, targets millennial generation as part of a strategy to increase contributions to the Original Revenue of Surabaya City. The millennial age group (19 to 40 years) has characteristics that reflect the transition between the previous generation (baby boomers) and afterwards (gene Z). Millennial generation behaviors that tend to be individually oriented are responded by providing selfies and offering activities that attract the interests of collective visitors. Using survey methods and measuring VALS (Values And Life Style) and frequency of media use by respondents, the result is that the psychographic profile of KBS visitors can be categorized as prone to Principle Oriented, whose lifestyle is characterized by having spiritual, pure value, likes to learn something new, has a traditional mindset, and do a fixed routine for a long time. With this profile, the main expectation of millennial for the availability of information at the Surabaya Zoo is information about animals, it is not a need for selfies.
\end{abstract}

Keywords: psychographic profile, millennial, media use

\begin{abstract}
ABSTRAK (Times New Roman12, ditebalkan, posisi ditengah)
Kebun Binatang Surabaya sebagai wahana rekreasi yang resmi dikelola oleh Pemerintah Kota Surabaya dan berstatus sebagai Perusahaan Daerah, menyasar generasi milenial sebagai bagian dari strategi meningkatkan kontribusi bagi Pendapatan Asli Daerah Kota Surabaya. Golongan usia millenial (19 s.d. 40 tahun) memiliki karakteristik yang mencerminkan transisi antara generasi sebelumnya (baby boomers) dengan sesudahnya (gen Z). Perilaku generasi Millenial yang cenderung berorientasi individual direspon dengan menyediakan taman Selfie dan menawarkan kegiatan-kegiatan yang menarik minat pengunjung dan bersifat kolektif. Dengan metode survey dan mengukur VALS (Values And Life Style) dan frekuensi penggunaan media oleh responden, diperoleh hasil bahwa profil psikografis pengunjung KBS dapat dikategorikan cenderung Principle Oriented, yang gaya hidupnya bercirikan antara lain: memiliki nilai spiritual, tidak memikirkan gengsi, suka belajar sesuatu yang baru, memiliki pola pikir tradisional, dan melakukan rutinitas yang tetap dalam jangka waktu yang lama. Dengan profil tersebut, ekspektasi utama dari milenial terhadap ketersediaan informasi Kebun Binatang Surabaya adalah informasi tentang satwa. Kebutuhan untuk selfie justru tidak terlalu tinggi.
\end{abstract}

Kata kunci: profil psikografis, milenial, penggunaan media

ISSN 2338 - 0861 (cetak); e-ISSN 2621 - 8712 (online)

website : http://spektrum.stikosa-aws.ac.id 


\section{PENDAHULUAN}

Penelitian ini akan mengungkapkan profil psikografis dan media usership (penggunaan media) di kelompok pengunjung Kebun Binatang Surabaya usia 19-39 tahun atau yang lazim disebut sebagai kelompok generasi millenial, atau sebutan lainnya: Gen Y. Menurut Strauss \& Howe (2012), generasi millenial adalah sebutan bagi kelompok penduduk yang lahir di antara tahun 1980an hingga 2000-an, pada penelitian ini, fokus diarahkan kepada kelompok pengunjung Kebun Binatang Surabaya yang lahir antara tahun tersebut. Pertimbangannya adalah, kelompok usia ini merupakan kelompok usia terbanyak dari total kunjungan ke Kebun Binatang Surabaya (KBS). Maulidiya (2019) mengutip pernyataan Chairul Anwar, Direktur Utama Perusahaan Daerah Taman Satwa Kebun Binatang Surabaya (PDTS KBS), mengatakan, trend jumlah pengunjung Kebun Binatang Surabaya terus bertambah tiap tahun, dengan rata-rata peningkatan 500 kunjungan tiap tahunnya. Sebagai ilustrasi, pada tahun 2017 pengunjung mencapai 1.560 , tahun 2018 mencapai 2.010.000, dan target 2.500 .000 pengunjung terpenuhi pada tahun 2019. Kenaikan jumlah pengunjung tersebut diantisipasi oleh pembenahan dan revitalisasi dari seluruh wilayah zona konservasi.

KBS memperluas fungsinya dari wahana konservasi menjadi sarana edukasi dan rekreasi dengan mobilisasi dengan melakukan kerjasama dengan pihak ketiga seperti Lembaga Pendidikan utamanya PAUD, TK, SD, sehingga tingkat kunjungan tidak hanya tinggi pada saat hari besar ataupun akhir pekan, namun pada hari kerja (Senin sampai Jumat) pun tetap ramai. Revitalisasi kandang hewan termasuk kandang komodo, harimau, burung Aves dan pulau bekantan, menurut Kurnia (2018) adalah bagian dari upaya untuk menarik minat pengunjung, terutama orang tua agar lebih mudah mendekatkan sekaligus mengenalkan hewan-hewan tersebut kepada anak-anaknya.

Dari penjelasan tersebut diasumsikan pengunjung yang termasuk dalam kelompok usia PAUD, TK atau SD berkunjung ke KBS dengan ditemani orang tuanya, yang berusia antara 20-39 tahun, sedangkan kelompok usia di bawah 20 tahun diasumsikan adalah kelompok remaja dewasa yang berstatus sebagai pelajar atau mahasiswa dan pekerja pemula. Meneliti profil psikografis pengunjung Kebun Binatang Surabaya dari kelompok usia millenial sangat menarik, karena kelompok usia ini memiliki karakter yang spesifik. Strauss dan Howe (2012) menjelaskan setidaknya terdapat tujuh karakter Millenial yaitu: spesial, terlindungi, percaya diri, berwawasan kelompok, konvensional, tahan tekanan dan mengejar pencapaian. Lyons (2004, dalam Putra, 2016) menyatakan, Millenials atau Generasi $\mathrm{Y}$ merupakan generasi yang tumbuh pada era internet booming, karena itu golongan ini banyak menggunakan teknologi komunikasi instant seperti email, SMS, instant messanging dan lain-lain. Twenge (2006) cenderung menggolongkan Millenial bersama anggota Generation $\mathrm{X}$ yang lebih muda, sebagai bagian dari "Generation Me". Twenge memberi atribut Millenial dengan karakter 1. Percaya diri dan toleransi, 2. Sadar 
akan haknya, dan 3. Cenderung narsistis.

Karakteristik Millenials tersebut direspon oleh pengelola Kebun Binatang Surabaya melalui program revitalisasi sejumlah wahana, tidak hanya kandang hewan tapi juga mengakomodir kebutuhan pengunjung dengan fasilitas seperti: Tunggang Satwa, di mana pengunjung dapat berfoto saat menunggang di atas punggung gajah atau onta yang diberi aksesoris sedemikian rupa. Kebun Binatang Surabaya juga menyediakan wahana Taman Selfie dan sejumlah spot khusus untuk berfoto, sebagai bagian dari memfasilitasi pengunjung golongan Millenials yang cenderung narsisistik.

Profil Psikografis pengunjung

Kebun Binatang Surabaya dari golongan Millenials pada dasarnya merupakan penggambaran perilaku pengunjung tersebut berdasarkan gaya hidupnya. Lebih jauh, penelitian ini juga akan mengungkap tentang bagaimana penggunaan media (media usership) kelompok ini. Yang dimaksud dengan penggunaan media dalam hal ini perilaku Millenials pengunjung Kebun Binatang Surabaya dalam memanfaatkan media untuk kebutuhannya sehari-hari, termasuk untuk mendapatkan informasi, menjalin relasi dan memfasilitasi gaya hidupnya. Secara sederhana, identifikasi permasalahan dalam penelitian ini adalah:

1. Bagaimana profil psikografis pengunjung Kebun Binatang Surabaya dari kelompok millenial?

2. Bagaimana perilaku penggunaan media (media use) pada pengunjung Kebun Binatang Surabaya dari kelompok millenial?

\section{METODE PENELITIAN}

Penelitian ini menggunakan pendekatan kuantitatif, dengan metode survey. Survey merupakan suatu cara melakukan pengamatan di mana indikator mengenai variabel adalah jawaban-jawaban terhadap pertanyaan yang diberikan kepada responden baik secara lisan maupun tertulis.

Survey dilakukan pada bulan Oktober 2019 di Kebun Binatang Surabaya, terbagi menjadi 3 waktu, yakni hari kerja dan akhir pekan. Sampel Responden ditentukan melalui teknik purposive sampling dan accidental sampling, jumlah responden 100 orang. Analisis data dilakukan dengan bantuan Statistik Deskriptif.

\section{HASIL DAN PEMBAHASAN Profil Demografis Pengunjung KBS dari Kelompok Milenial}

Mengacu pada penetapan Badan Pusat Statistik tentang batasan usia generasi milenial, responden penelitian ini adalah pengunjung Kebun Binatang Surabaya yang berumur antara 18-40 tahun, atau dilahirkan antara tahun 1980 sampai dengan 2000. Di bawah ini ditampilkan profil responden berdasarkan data demografisnya, yang meliputi usia, jenis kelamin, tingkat pendidikan dan domisili Responden. Tabel 5.1 adalah profil Responden berdasarkan Usia dan Jenis Kelamin. Usia Responden dibedakan menjadi tiga, yaitu 1 . Kelahiran tahun 1980-an (19-25 tahun), 2. Kelahiran tahun 1990-an (26-32 tahun), dan 3. Kelahiran tahun 2000-an (27-40 tahun). Sedangkan jenis kelamin responden dibedakan atas Laki-laki dan Perempuan.

Jumlah total responden adalah 100 orang dengan komposisi 37 orang 
responden laki-laki dan 63 responden perempuan. Responden laki-laki terbanyak berusia antara 26-32 tahun (22\%), sama dengan rentang usia terbanyak pada responden perempuan, yaitu antara 26-32 tahun (41\%).

Selanjutnya dari sisi tingkat pendidikan, responden laki-laki yang merupakan lulusan SMA sebanyak $12 \%$ sedangkan responden perempuan lulusan SMA sebanyak 29\%. Adapun lulusan S1 (sarjana) responden perempuan 25 orang (25\%), dan responden laki-laki 20 orang $(20 \%)$.

Berdasarkan agama/ kepercayaannya, sebagian besar (81\%) responden beragama Islam, ada 9 orang beragama Katolik, 8 orang beragama Kristen, sedangkan responden beragama Hindu serta penghayat kepercayaan, masingmasing 1 orang.

Pengunjung Kebun Binatang Surabaya pada periode pengumpulan data dalam penelitian ini, yaitu bulan Oktober 2019, pada hari kerja dan akhir pekan, didominasi oleh wisatawan yang berasal dari kota Surabaya sendiri 53\%. Pengunjung dari luar kota Surabaya 19\%, dari Trenggalek, Tulungagung, Blitar, Kediri, Malang, Lumajang, Jember, Banyuwangi, Bondowoso, Situbondo, Probolinggo, Pasuruan, Sidoarjo, Mojokerto, Jombang, Nganjuk, Madiun, Magetan, Ngawi, Bojonegoro, Tuban, Lamongan, Gresik dan Bangkalan. Pengunjung dari luar Jawa timur 28\%, berasal dari Gorontalo, Jakarta, Jawa Barat, Jawa Tengah, Kalimantan Barat, Kalimantan Tengah, Kalimantan Timur, Bali, NTT, Papua Barat dan Sulawesi Selatan. Adapun Responden asal kota Surabaya, berdomisili di 24 dari 31 kecamatan yang ada di Surabaya, yakni Benowo, Bubutan, Bulak, Dukuh Pakis, Gayungan, Gubeng, Gunung Anyar, Jambangan, Karangpilang, Kenjeran, Krembangan, Lakarsantri, Rungkut, Sambikerep, Sawahan, Semampir, Sukolilo, Sukomanunggal, Tambaksari, Tandes, Tegalsari, Tenggilis, Wiyung, Wonocolo dan Wonokromo.

Responden yang menjadi
sasaran peneliti merupakan pengunjung Milenial yang mendatangi Kebun Binatang Surabaya sedikitnya dalam satu tahun terakhir. Hasil temua menunjukkan, responden yang ditemui pada bulan Oktober 2019 tersebut sebagian merupakan pengunjung reguler di Kebun Binatang Surabaya. Meskipun sebagian besar melakukan kunjungan terakhir ke KBS lebih dari 1 bulan sebelum tanggal pengumpulan data, namun frekuensi kunjungan mereka rata-rata lebih dari satu kali. Artinya, Milenial cenderung melakukan kunjungan ulang (repeat visit) ke KBS.

\section{Profil Psikografis Pengunjung KBS dari Kelompok Milenial}

Jika dilihat dari rata-rata pengeluaran per-bulan yang di bawah angka UMP Kota Surabaya, pengunjung Kebun Binatang Surabaya dapat dikategorikan berasal dari kalangan Sosial Ekonomi menengah ke bawah. Pengeluaran rata-rata perbulan responden antara satu hingga empat juta rupiah. Diagram 1 memberikan gambaran rata-rata pengeluaran responden dalam 1 bulan.

Yang menarik, dengan pengeluaran tersebut, responden menganggap bahwa di antara kebutuhan mereka yang harus terpenuhi adalah rekreasi. Sebagian besar (47\%) pengunjung KBS 
kelompok milenial menyatakan bahwa urgensi rekreasi bagi mereka adalah sangat penting.

\section{PENGELUARAN RATA-RATA PER-... — $<$ dari Rp 1.000.000 - Rp 1.000.000 - Rp 2.000.000 $\begin{array}{llllll}32 & 27 & 27 & 4 & 5 & 4\end{array}$ 50 \\ Gbr. 1 Rata-rata Pengeluaran Per- Bulan Pengunjung KBS Golongan Milenial}

\section{Sumber: Data Primer, Diolah Peneliti}

Rekreasi ke Kebun Binatang Surabaya bagi Milenial termasuk yang dianggap penting. Sebagian besar (52\%) responden menyatakan, berkunjung ke Kebun Binatang Surabaya itu penting, 30\% menyatakan biasa-biasa saja dan 19\% menyatakan sangat penting.

URGENSI BERKUNJUNG KE KBS BAGI KELOMPOK MILENIALS

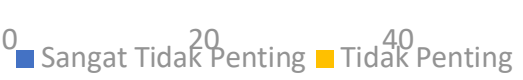

$$
\begin{aligned}
& \text { aiasa } \quad \text { Penting } \\
& \text { — Sangat Penting }
\end{aligned}
$$

\section{Gbr 2. Urgensi Berkunjung ke KBS bagi Kelompok Milenial} Sumber: Data Primer, Diolah Peneliti

Dari aspek VALS (Value and Lifestyle) sebagai salah satu elemen dari profiling secara psikografis. Jika sebelumnya telah dipaparkan dari dimensi sumber daya (resources) yang meliputi sisi pendapatan (income), pendidikan, kepercayaan diri, kesehatan, keinginan membeli dan energi. Di bawah ini deskripsi gaya hidup pengunjung Kebun Binatang Surabaya kelompok milenials dilihat dari sisi orientasi hidup, yang meliputi prinsip (principle), status dan tindakan.

Terdapat perbedaan orientasi gaya hidup suatu kelompok segmen, yang terbagi empat (Anandan, 2006, 105), yakni: Pertama, Principle Oriented dengan ciri: lebih bijak terhadap hal-hal yang bernilai secara spiritual, tidak terlalu memikirkan image dan gengsi, suka belajar dan mengenai sesuatu yang baru (fullfilled). Kelompok berorientasi prinsip juga memiliki pola pikir yang kolot dan tradisional, lambat beradaptasi dengan hal-hal baru, memiliki suatu rutinitas yang cenderung tetap untuk jangka waktu lama (Believers).

Berikutnya, yang ke-dua adalah Status Oriented, di mana ciriciri kelompok segmen ini adalah peduli citra diri, mudah terpengaruh, tertarik pada produk-produk mahal dan suka segala hal yang dapat mengangkat status sosialnya (Achievers). Kelompok ini, meskipun jaim (menjaga image dirinya) tapi masih cenderung memiliki semangat dan ambisi untuk meraih apa yang diinginkannya dengan segala usaha sendiri yang keras, mereka pintar mencari uang (Strivers).

Kelompok ke-tiga, Action Oriented. Yang termasuk dalam kategori ini adalah orang-orang yang suka mengikuti tren dan mencoba halhal baru, perilaku konsumtif mereka terhadap hal-hal baru sangat agresif dan tidak disertai pertimbangan. Mereka tidak tertarik pada kemewahan dan tidak tertarik pada 
apa yang orang pikirkan tentang mereka namun suka untuk berbelanja hal-hal yang bernilai dan tahan lama untuk kenyamanannya sendiri (Makers).

Kelompok terakhir adalah Resourced Oriented, di mana ciricirinya adalah Konsumen dengan tingkat pendapatan yang tertinggi dan memiliki banyak sumber sehingga dapat menuruti keinginannya sendiri, image menjadi sangat penting bagi mereka sehingga cenderung membeli produk yang lebih baik dalam hidup (Actualisers). Resources Oriented juga meliputi golongan tipe Konsumen dengan tingkat pendapatan yang terendah dan sumber yang sedikit untuk diikutkan pada orientasi konsumen. Kemampuan ekonomi yang terbatas membuat mereka mudah untuk loyal terhadap merk produk yang berorientasi pada harga yang murah (Strugglers).

Untuk dapat mengidentifikasi profil psikografis pengunjung Kebun Binatang Surabaya Kelompok Millenials, di bawah ini ada beberapa indikator yang dapat digunakan sebagai dasar mengkategorikan orientasi gaya hidup pengunjung Kebun Binatang Surabaya kelompok Millenial. Pertama, bagaimana mereka mengisi waktu luangnya. Pada Gambar 3 dapat dilihat, ada 13 aktivitas yang dilakukan Milenial pengunjung KBS di waktu luang (tidak sedang bekerja atau di luar jam kerja). Urutan pertama adalah bermain media sosial (28\%), kemudian melakukan hobi (23\%). Kegiatan di waktu luang para Milenial pengunjung Kebun Binatang Surabaya yang lain adalah: pergi ke pusat perbelanjaan (18\%), nonton TV (16\%), nonton bioskop (13\%), ke pantai (13\%), browsing internet (13\%), mendaki gunung $(12 \%)$, membaca buku $(8 \%)$, dan berkunjung ke kerabat (8\%).
Meskipun prosentasenya kecil, yang artinya tidak banyak dilakukan oleh Milenials pengunjung KBS, aktivitas mendengarkan radio termasuk yang dilakukan di waktu luang (3\%), dan ada pula yang tetap produktif di waktu luangnya dengan cara mengambil kursus (3\%).

\section{KEGIATAN PENGUNJUNG MILENIALS KBS DI WAKTU LUANG \\ 50

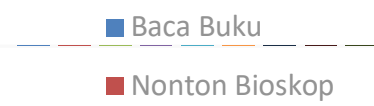

\section{Gbr. 3. Kegiatan Pengunjung} Milenial KBS di Waktu Luang Sumber: Data Primer, Diolah Peneliti

Bagi pengunjung KBS kelompok milenial, daya tarik Kebun Binatang Surabaya sebagai tempat rekreasi terutama terletak pada keragaman satwanya. Selain itu, harga murah adalah pertimbangan berikutnya. Pada Gambar 4 dapat dilihat $69 \%$ responden menyatakan tertarik mengunjungi KBS karena ingin melihat sendiri secara langsung keragaman satwa di sana. $21 \%$ pengunjung tertarik karena harga tiket masuknya yang relatif murah (Rp 15.000,- per orang). Selain itu, yang menjadi daya tarik KBS bagi kelompok milenial adalah: flora-fauna (20\%), nilai sejarahnya (12\%), tempatnya yang bersih (11\%), ada tempat selfie (11\%), menunggang satwa (9\%), berkunjung ke museum satwa (8\%), merupakan tempat yang aman bagi anak (8\%), tempat duduk yang nyaman $(7 \%)$, bisa memberi makan satwa (5\%), acaranya yang menarik (2\%). Terkait acara yang 
menarik, pihak pengelola KBS memang secara berkala merancang acara yang bisa dinikmati pengunjung baik yang reguler maupun yang khusus datang untuk acara tersebut, termasuk contohnya: pagelaran musik, workshop, bedah buku, pameran dan acara-acara khusus yang hanya diadakan di hari-hari besar seperti Natal, Lebaran serta hari libur sekolah.

\section{DAYA TARIK KEBUN BINATANG SURABAYA BAGI PENGUNJUNG MILENIALS 100

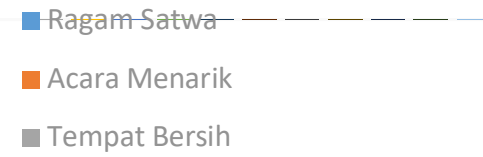

\section{Gbr 4. Daya Tarik Kebun Binatang Surabaya bagi Pengunjung Kelompok Milenial Sumber: Data Primer, Diolah Peneliti}

Pengunjung kelompok milenial memiliki ekspektasi agar Kebun Binatang Surabaya memperbaiki atau meningkatkan kualitas sejumlah fasilitasnya, terutama keragaman satwanya (34\%). Selain itu, mereka juga ingin penambahan fasilitas free WiFi (26\%), fasilitas tempat duduk (15\%), kantin (7\%), spot foto selfie (4\%). Yang menarik adalah, kepedulian terhadap satwa pada pengunjung kelompok milenial ini cukup tinggi, $25 \%$ responden mengharapkan pengelola Kebun Binatang Surabaya lebih meningkatkan perhatian pada kesejahteraan satwa (animal welfare).

\begin{tabular}{lcr}
\multicolumn{2}{c}{ Harapan $\quad$ ini } & dapat \\
diasumsikan & sebagai & sebuah \\
manifestasi & keprihatinan & atas
\end{tabular}

pemberitaan tentang pengelolaan satwa di KBS beberapa waktu lalu, di mana media melaporkan adanya hewan koleksi yang mati dalam keadaan tidak terurus dan sakit. Pengunjung milenial mengharapkan, pengelola KBS juga memberikan informasi-informasi yang mereka butuhkan, termasuk info promosi (5\%), info harga (7\%), info acara (2\%). Informasi yang sangat diharapkan disediakan oleh pengelola KBS juga info satwa (18\%) dan info sejarah Kebun Binatang Surabaya $(12 \%)$.

Sejauh ini, informasi-
informasi yang dibutuhkan
pengunjung kelompok milenial
tersebut sudah tersedia dalam bentuk
signboard seperti dapat dilihat pada
gambar 5.

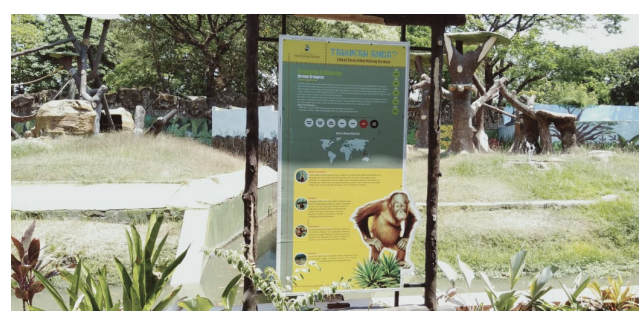

\section{Gbr 5. Papan Edukasi Satwa di Kebun Binatang Surabaya Sumber: Dokumentasi Peneliti}

Papan Edukasi memuat informasi tentang satwa, antara lain nama Spesies, nama latin Spesies, peta penyebaran, ciri fisik dan lain-lain, dalam bentu infografis yang dicetak pada papan kayu yang diletakkan di beberapa lokasi strategis. Selain papan edukasi juga terdapat papan petunjuk arah yang cukup informatif.

Pengunjung Kebun Binatang kelompok milenial menginginkan agar kebersihan KBS ditingkatkan, karena pada kenyataannya, produksi sampah pengunjung Kebun Binatang Surabaya pada hari-hari libur maupun akhir 
pekan dapat dikatakan tak terkendali. Pengunjung membuang sampah tidak pada tempatnya dan dalam jumlah yang cukup besar. Sampah pengunjung terutama berupa sampah plastik bekas kemasan makanan dan minuman.

Dalam persepsi pengunjung milenial, kebersihan KBS merupakan tanggung jawab bersama pengunjung, pengelola Kebun Binatang Surabaya, petugas kebersihan, warga kota Surabaya dan Pemkot Surabaya. Sebanyak $\quad 32 \% \quad$ responden menyatakan pengunjunglah yang paling bertanggung jawab terhadap pemeliharaan kebersihan di area KBS. Artinya, telah ada kesadaran di kalangan milenial pengunjung Kebun Binatang Surabaya tentang pentingnya partisipasi mereka dalam pemeliharaan kebersihan di Kebun Binatang Surabaya. Namun, pengunjung KBS terdiri dari berbagai kalangan yang memiliki tingkat kesadaran berbeda tentang pemeliharaan kebersihan di Kebun Binatang Surabaya yang merupakan ruang publik, yang harus dijaga secara kolektif.

PERSEPSI PENGUNJUNG
MILENIALS TENTANG
PENANGGUNG JAWAB...
@ Petugas Kebersihan $\square$ Pengelola KBS
Gbr 6. Persepsi Pengunjung
Milenial Kebun Binatang Surabaya
Sumber: Data Primer, diolah Peneliti
Profil psikografis pengunjung
Kebun Binatang Surabaya dari
kelompok millenial dapat

diidentifikasi berbasis VALS (Value Anda Lifestyle). Di bawah ini terdapat empat Tabel yang mendeskripsikan Value (nilai) yang melekat pada individu dari golongan milenial dan indikator yang merupakan manifestasi gaya hidup yang diungapkan oleh responden, berupa aktivitas-aktivitas yang dilakukannya sebagai pengunjung Kebun Binatang Surabaya.

Tabel 5. adalah kategori Principle Oriented. Berdasarkan prosentase pada tiap-tiap indikator, diperoleh angka 68\%, yang berarti profil psikografis pengunjung Kebun Binatang Surabaya golongan milenial memenuhi 68\% persyaratan kategori Principle Oriented. Gaya hidup golongan ini cenderung memiliki nilai spiritual, tidak memikirkan gengsi, suka belajar sesuatu yang baru, memiliki pola pikir tradisional, dan melakukan rutinitas yang tetap dalam jangka waktu yang lama.

Tabel 1. Keterpenuhan Kategori Psikografis Principle Oriented pada Pengunjung KBS Golongan Milenial

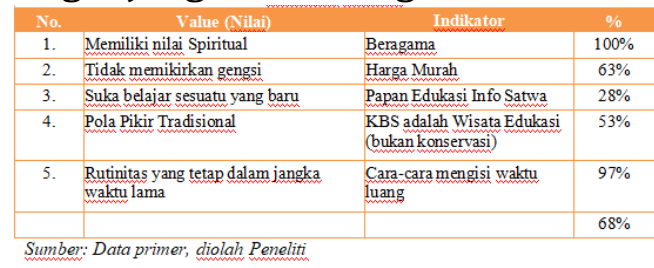

Tabel 2 adalah kategori Status Oriented. Berdasarkan prosentase pada tiap-tiap indikator, diperoleh angka 20\%, yang berarti profil psikografis pengunjung Kebun Binatang Surabaya golongan milenial memenuhi $20 \%$ persyaratan kategori Status Oriented. Gaya hidup golongan ini cenderung memiliki nilai peduli citra diri, mudah terpengaruh, tertarik produk mahal, suka segala sesuatu yang dapat mengangkat status sosialnya, bersemangat untuk meraih 
yang diinginkan dengan usaha sendiri (Strivers).

\section{Tabel 2. Keterpenuhan Kategori Psikografis Status Oriented pada Pengunjung KBS Golongan Milenial}

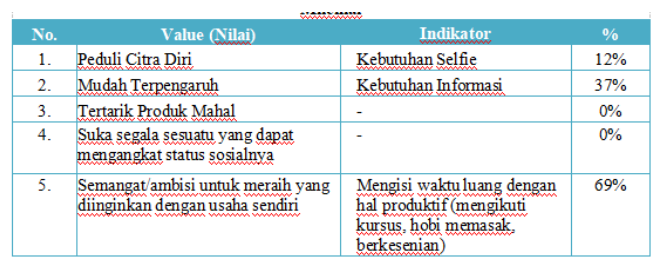

Tabel 3 adalah kategori Action Oriented. Berdasarkan prosentase pada tiap-tiap indikator, diperoleh angka 23\%, yang berarti profil psikografis pengunjung Kebun Binatang Surabaya golongan milenial memenuhi 23\% persyaratan kategori Action Oriented. Gaya hidup golongan ini cenderung suka mengikuti trend dan mencoba hal baru, berperilaku konsumtif tanpa pertimbangan. Ciri dari Action Oriented juga sebaliknya tidak tertarik kemewahan, tidak memikirkan opini orang lain tentang dirinya dan gemar berbelanja untuk menyenangkan atau kenyamanan diri sendiri (Makers).

Tabel 3. Keterpenuhan Kategori Psikografis Action Oriented pada Pengunjung KBS Golongan Milenial

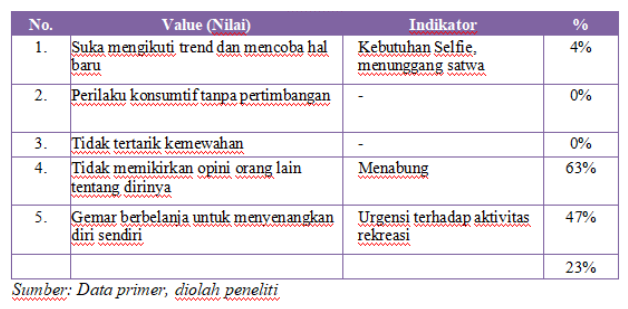

Tabel 4 dalah kategori Resourced Oriented. Berdasarkan prosentase pada tiap-tiap indikator, diperoleh angka $17 \%$, yang berarti profil psikografis pengunjung Kebun Binatang Surabaya golongan milenial memenuhi $17 \%$ persyaratan kategori
Resourced Oriented. Gaya hidup golongan ini cenderung memiliki tingkat pendapatan tinggi dan berbagai sumber pendapatan (Actualisers), Mementingkan image, cenderung berbelanja barang mewah. Ciri dari Resourced Oriented juga sebaliknya Pendapatan rendah dan sumber pendapatan sedikit, kemampuan ekonomi terbatas dan Loyal terhadap produk dengan harga murah (Struglers).

Tabel 3. Keterpenuhan Kategori Psikografis Resourced Oriented pada Pengunjung KBS Golongan Milenial

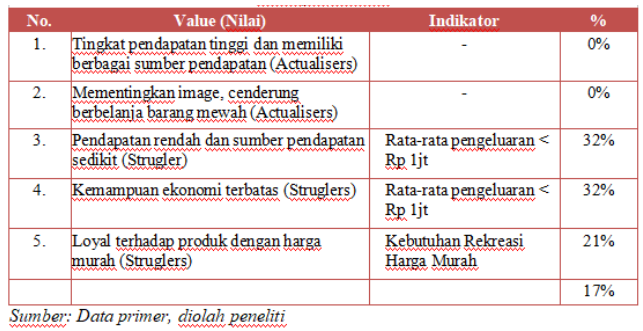

\section{Media Use Pengunjung KBS Golongan Milenial}

Media usership atau penggunaan media oleh suatu segmen khalayak umumnya mengacu pada gaya hidup segmen khalayak tersebut. Mengingat informasi telah menjadi komoditi yang dikonsumsi oleh khalayak media. Dalam Teori Uses \& Gratification, perhatian tertuju pada "apa yang dilakukan khalayak terhadap media" sebagai bentuk perilaku individu sebagai khalayak aktif. Asumsi teori ini yaitu, khalayak aktif dalam memenuhi kebutuhannya dan dorongannya. Mereka menggunakan media karena memiliki tujuan tertentu. Karena memiliki sumber-sumber lain untuk memenuhi kebutuhannya, mereka berinisiatif mengaitkan kebutuhan dan pilihan media. Konsumsi media dapat memenuhi berbagai kebutuhan 
meskipun isi media tidak dapat digunakan untuk memprediksi pola gratifikasi secara tepat. Keaktifan khalayak ditandai dengan pilihanpilihan yang dibuat khalayak yang dilatarbelakangi oleh alasan-alasan yang berbeda. Alasan-alasan yang dimaksud misalnya alasan untuk keluar dari masalah atau aktivitas rutin (escape), mencari informasi (information seeking), mencari hiburan (entertainment), membangun hubungan sosial (social relationship), dan membangun identitas pribadi (personal identity).

Dalam penelitian ini, penggunaan media oleh pengunjung Kebun Binatang Surabaya kelompok Milenial meliputi media yang digunakan responden dan bagaimana penggunaan media tersebut dapat memuaskan kebutuhan responden atas kebutuhan informasi mengenai Kebun Binatang Surbaya. Milenial pengunjung KBS cenderung menggunakan komunikasi interpersonal seperti keluarga sebagai sumber informasi utama tentang Kebun Binatang Surabaya (39\%), diikuti oleh teman (28\%) dan tour guide $(1 \%)$. Berikutnya, baru mediamedia konvensional seperti radio (9\%) dan TV (8\%). Media baru yang mendominasi adalah Media sosial (medsos) sebesar 24\%, sedangkan website KBS hanya diakses sebanyak $5 \%$ responden. Media luar ruang yang dikonsumsi responden seperti billboard (3\%) dan poster (1\%).

Di luar informasi tentang Kebun Binatang Surabaya, responden mengkonsumsi media yang cukup beragam untuk memenuhi kebutuhannya akan informasi, termasuk di dalamnya media konvensional dan media baru. Sumber informasi utama pengunjung KBS kelompok milenial adalah platform media sosial Instagram (60\%), diikuti Facebook (31\%), Twitter (8\%). Media baru dengan platform lain yang dikonsumsi responden adalah website $(12 \%)$ dan microsite (5\%) seperti Line Today, Babe.

\section{Gbr 7. Sumber Informasi yang Dikonsumsi Pengunjung Milenial Kebun Binatang Surabaya}

SUMBER INFORMASI YANG DIKONSUMSI PENGUNJUNG KEBUN...

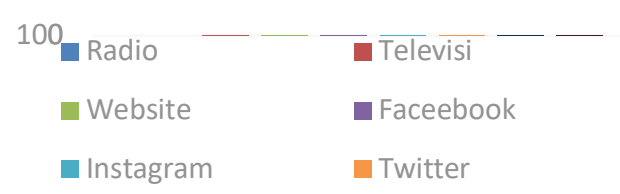

Sumber: Data primer, diolah peneliti

Pada gambar 8 dapat dilihat preferensi pengunjung milenial terhadap media, artinya media yang lebih disukai oleh responden dan lokasi yang lebih disukai untuk mengakses informasi dari mediamedia tersebut. Media yang paling sering digunakan oleh responden adalah telepon genggam atau tablet, yang diakses di mana saja setiap ada kesempatan (38\%) dan di rumah (37\%). Koran, radio dan TV masih merupakan media pilihan, namun dengan tingkat akses yang rendah. Responden mengakses media konvensional koran/radio/TV di rumah $(20 \%)$, di tempat kerja $(8 \%)$ dan di kendaraan pribadi (3\%) dan radio di kendaraan umum (2\%). Media lain yang digunakan adalah komputer personal dan/atau laptop, diakses di rumah (14\%) dan di kantor (4\%). 


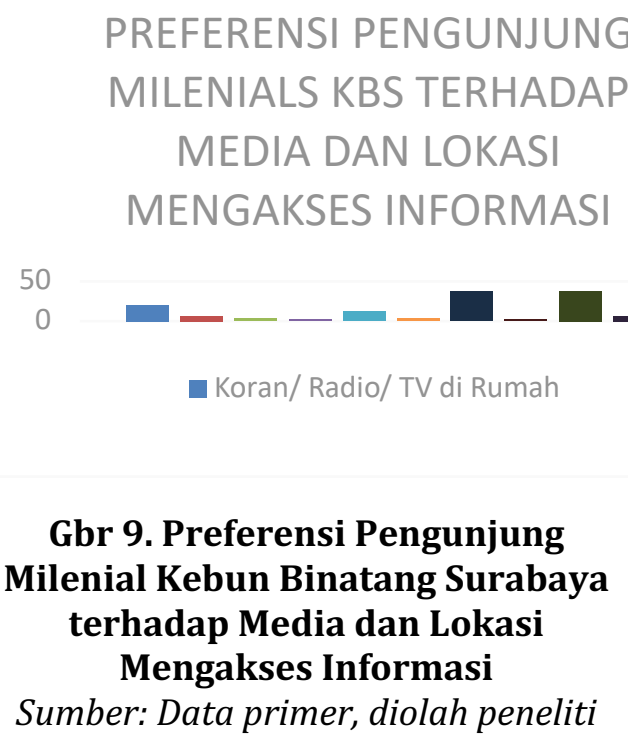

Alasan penggunaan media
dalam aliran empat fungsional
menyebut empat fungsi media dalam
memenuhi kebutuhan khalayak.
Menurut Laswell dan Wright empat
fungsi itu adalah pengawasan
lingkungan (surveillance), hubungan
sosial (correlation), hiburan
(entertainment), dan transmisi
budaya/ cultural transmission. Aliran
empat funsgional ini melihat, bahwa
ketika media baru berbasis internet
dengan berbagai platform
bermunculan (misalnya media sosial,
video game, microsite, blog, vlog),
maka keempat fungsi tersebut
melekat dan khalayak menggunakan
media-media tersebut dalam rangka
untuk memuaskan kebutuhannya
sebagai pengawas, mendapatkan
hubungan, mendapatkan hiburan dan
melibatkan diri dalam suatu proses
transmisi budaya.

Bagi pengunjung milenial, informasi tentanag Kebun Binatang Surabaya adalah informasi yang memiliki muatan yang berkemampuan memberikan kepuasan-kepuasan tersebut. Pada gambar 10 dapat dilihat, bagaimana

tingkat kepuasan responden terhadap ketersediaan informasi tentang Kebun Binatang Surabaya. 72\% responden menyatakan cukup memenuhi kebutuhan, $\quad 23 \% \quad$ responden menyatakan memenuhi kebutuhan, $7 \%$ sangat memenuhi kebutuhan. Sisanya $3 \%$ merasa bahwa ketersediaan informasi KBS tidak memenuhi kebutuhan dan 2\% sangat tidak memenuhi kebutuhan. Dari hasil ini dapat dilihat bahwa pada dasarnya pengunjung memerlukan informasi tentang Kebun Binatang Surabaya lebih dari ketersediaan yang sekarang dapat mereka akses dan nikmati

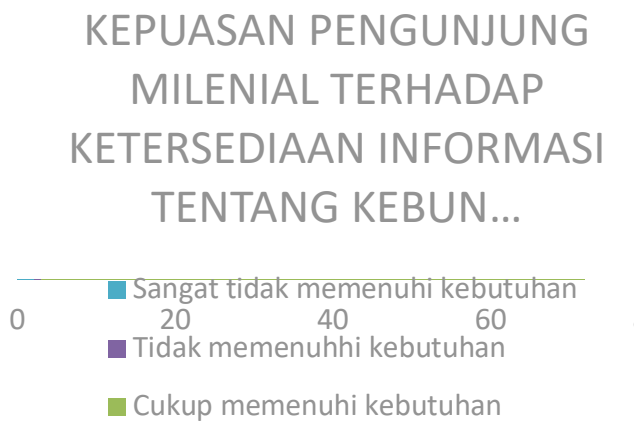

\section{Gbr. 10. Kepuasan Pengunjung Milenial terhadap Ketersediaan Informasi tentang Kebun Binatang Surabaya \\ Sumber: Data primer, diolah peneliti}

Ekspektasi atau harapan
pengunjung milenial tentang
informasi apa saja yang seharusnya
disediakan oleh Kebun Binatang
Surabaya dapat dilihat pada tabel 10.
Yang pertama adalah informasi
tentang perkembangan kondisi satwa
(54\%). Bila mengacu pada profil
psikografis pengunjung yang memiliki
kecenderungan principle oriented, ini
relevan di mana pengunjung milenial
memiliki karakteristik suka
mempelajari sesuatu yang baru.
Informasi lain yang diharapkan oleh

ISSN 2338 - 0861 (cetak); e-ISSN 2621 - 8712 (online)

website : http://spektrum.stikosa-aws.ac.id 
pengunjung milenial adalah informasi tentang aktivitas atau kegiatan termasuk acara-acara temporal yang diselenggarakan di Kebun Binatang Surabaya (34\%), promosi untuk pengunjung (28\%). Selanjutnya informasi yang membantu responden untuk melakukan antisipasi atau perencanaan, seperti jadwal harian termasuk tingkat/kepadatan kunjungan harian (14\%). Informasi lain-lain (5\%) di luar yang disebut responden tidak diidentifikasi secara khusus, lebih pada materi yang spesifik hanya dapat disediakan oleh KBS dan belum pernah diketahui oleh pengunjung, materi yang sama sekali baru dan kejutan.

EKSPEKTASI PENGUNJUNG MILENIAL TENTANG INFORMASI WAJIB YANG HARUS DISEDIAKAN KBS

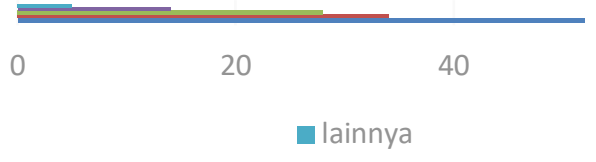

Gbr 11.

Ekspektasi Pengunjung Milenial tentang Informasi yang Harus Disediakan Kebun Binatang Surabaya

\section{KESIMPULAN}

Sebagai kesimpulan dari penelitian ini, berikut rumusan yang menjawab permasalahan yang dikemukan peneliti:

1. Profil Psikografis

a) Pengunjung Kebun Binatang Surabaya golongan milenial memenuhi $68 \%$ persyaratan kategori Principle Oriented. Gaya hidup golongan ini cenderung memiliki nilai spiritual, tidak memikirkan gengsi, suka belajar sesuatu yang baru, memiliki pola pikir tradisional, dan melakukan rutinitas yang tetap dalam jangka waktu yang lama.

b) Pengunjung Kebun Binatang Surabaya golongan milenial memenuhi $20 \%$ persyaratan kategori Status Oriented. Gaya hidup golongan ini cenderung memiliki nilai peduli citra diri, mudah terpengaruh, tertarik produk mahal, suka segala sesuatu yang dapat mengangkat status sosialnya, bersemangat untuk meraih yang diinginkan dengan usaha sendiri (Strivers).

c) Pengunjung Kebun Binatang Surabaya golongan milenial memenuhi $23 \%$ persyaratan kategori Action Oriented. Gaya hidup golongan ini cenderung suka mengikuti trend dan mencoba hal baru, berperilaku konsumtif tanpa pertimbangan. Ciri dari Action Oriented juga sebaliknya tidak tertarik kemewahan, tidak memikirkan opini orang lain tentang dirinya dan gemar berbelanja untuk menyenangkan atau kenyamanan diri sendiri (Makers).

d) Pengunjung Kebun Binatang Surabaya golongan milenial memenuhi $17 \%$ persyaratan kategori Resourced Oriented. Gaya hidup golongan ini cenderung memiliki tingkat pendapatan tinggi dan berbagai sumber pendapatan (Actualisers), Mementingkan image, cenderung berbelanja 
barang mewah. Ciri dari Resourced Oriented juga sebaliknya Pendapatan rendah dan sumber pendapatan sedikit, kemampuan ekonomi terbatas dan Loyal terhadap produk dengan harga murah (Struglers).

2. Media Usership

a) Penggunaan media oleh Pengunjung Kebun Binatang Surabaya golongan milenial didominasi oleh media baru yaitu media berbasis internet dengan platform media sosial (Instagram dan Facebook), diikuti media baru dengan platform website dan microsite. Media konvensional yang masih tinggi penggunaannya di kalangan ini adalah televisi.

b) Penggunaan media konvensional radio dan TV lebih cenderung digunakan ketika milenial berada di rumah. Sedangkan media baru dengan berbagai platform (medsos, website, microsite) diakses dengan menggunakan perangkat telepon genggam dan tablet di manapun setiap ada kesempatan dan di rumah.

c) Kepuasan pengunjung milenial terhadap ketersediaan informasi Kebun Binatang Surabaya adalah cukup, artinya belum sampai pada tahap puas atau sangat puas.

d) Ekspektasi pengunjung milenial terhadap ketersediaan informasi Kebun Binatang Surabaya terutama adalan informasi tentang perkembangan satwa. Ekspektasi ini relevan dengan profil psikografis golongan ini yang cenderung principle oriented, dengan ciri-ciri suka belajar sesuatu yang baru.

\section{DAFTAR PUSTAKA}

Anandan, C., M. Prasanna Mohanraj, S. Madhu. (2006), A Study of the Impact of Values and Lifestyles (VALS) on Brand Loyalty with Special Reference to English Newspaper, Vilakshan XIMB Journal of Management, India

Aprilia, Djayanti. (2014) Aryo Bayu Wibisono, Rebranding Kebun Binatang Surabaya, Jurnal Createvitas Vol.3, No.1, Januari 2014:29-42

Devi Ariani Putri. D, Subhan Ramdlani, Indyah Martiningrum, Kebun Binatang Surabaya (Perancangan Ulang dengan Pengoptimalan Ruang Terbuka Hijau)

Faiq, Nuraini, Manajemen Minta Harga Tiket KBS Masuk Dinaikan, Begini Jawaban DPRD Surabaya, https://surabaya.tribunnews.com /2019/07/31/manajemen-mintaharga-tiket-kbs-masuk-dinaikanbegini-jawaban-dprd-surabaya, surabaya.tribunnews.com, 31 Juli 2019, diunduh 31 oktober 2019.

Ginanjar, Dimas (ed). (2019), Kebun Binatang Surabaya Penuhi Target 180 Ribu Pengunjung Sepanjang Libur Lebaran, https://www.jawapos.com/surab aya/25/06/2019/kebun-

binatang-surabaya-penuhi-target180-ribu-pengunjung/, diunduh 13 Oktober 2019.

Horovitz, Bruce (4 Mei 2012). "After Gen X, Millennials, what should next generation be?". USA Today. Diakses tanggal 24 Agustus 2019. 


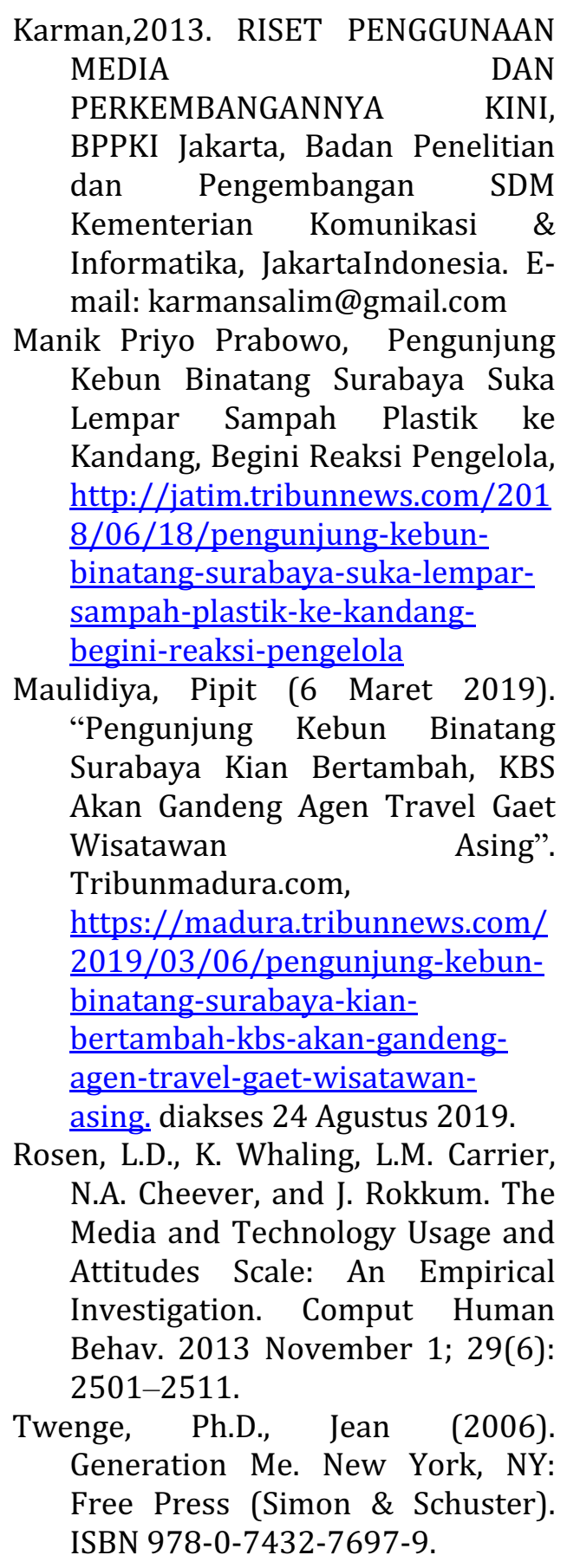

ISSN 2338 - 0861 (cetak); e-ISSN 2621 - 8712 (online) website : http://spektrum.stikosa-aws.ac.id 